ORIGINAL PROF-2221

\title{
ANAEMIA IN PREGNANCY;
}

\section{A STUDY OF PREVALENCE AND RISK FACTORS IN ANTENATAL CARE ATTENDEES AT ABSH GUJRAT}

Dr. Shabana Kalsoom, Dr. Shahida Hussain Tarar, Dr. Tahmina Naz

ABSTRACT... Background: Anaemia in pregnancy is an important public health problem especially in developing countries. It is a major cause of maternal morbidity and mortality, and also has a significant impact on health of foetus. The causative factors vary in different communities. Objectives and Methods: The purpose of study was to determine the prevalence and risk factors of anaemia among pregnant women receiving antenatal care at Aziz Bhatti Shaheed Hospital Gujrat. The attending doctor filled a Proforma at the first antenatal visit and blood sample was also drawn for complete blood counts. Results: Out of 560 women studied,419(74.8\%) women were anaemic .Anaemia was more prevalent in multigravidae (77.6\%) than in primigravidae (69.3\%).Regarding severity $69.9 \%$ mild, $26.7 \%$ moderate and $3.3 \%$ cases were of severe anaemia respectively. The severity increased with increasing parity. The prevalence also increased with decreasing birth intervals $(p=0.001)$ and late booking $(p=0.002)$. Anaemia was more common among uneducated $(78.6 \%)$ or those educated up to primary $(72.7 \%)$. Intake of meat/chicken less than 2times/week $(p=0.01)$ and PICA $(p=0.005)$ were also the risk factors for anaemia development in pregnancy. Conclusions: The prevalence of anaemia in antenatal care attendees of ABSH is very high. Frequent child birth with lack of birth spacing, late booking, low educational status and poor dietary habits are the major risk factors that need urgent attention of health care providers.

Key words: Anaemia, pregnant women, risk factors, prevalence.

Article Citation

Kalsoom S, Tarar SH, Naz T. Anaemia in pregnancy; a study of prevalence and risk factors in antenatal care attendees at ABSH Gujrat. Professional Med J 2013;20(5): 736-742.

\section{INTRODUCTION}

Anaemia during pregnancy is a global problem affecting almost half of pregnant women. The WHO regions of Africa and South-East Asia have the highest risk'. Anaemia prevalence during pregnancy differed from $18 \%$ in developed countries to $75 \%$ in SouthAsia ${ }^{2}$. The world health organization defines anaemia in pregnancy as haemoglobin concentration less than $\mathrm{Ig} / \mathrm{dl}$ and a haematocrit below $33 \%^{3}$. It is further categorized according to severity into mild (9$10.9 \mathrm{~g} / \mathrm{dl})$, moderate $(7-8.9 \mathrm{~g} / \mathrm{dl})$ and severe $(<7 \mathrm{~g} / \mathrm{dl})$ degree of anaemia. The complications increase with increasing severity.

Anaemia during pregnancy is associated with increased maternal morbidity and mortality. In India anaemia is directly or indirectly responsible for $40 \%$ of maternal deaths. There is 8-10 fold increase in maternal mortality rate when haemoglobin falls below $5 \mathrm{~g} / \mathrm{dl}^{4}$. Death from anaemia is the result of heart failure, shock or infection. Anaemic women do not tolerate the blood loss to same degree as healthy women ${ }^{5}$.
Maternal anaemia is associated with increased risk of adverse perinatal outcomes such as foetal anaemia, low birth weight; preterm birth and still-birth ${ }^{6-11}$. Neonatal effects include low iron stores, poor cognitive development and low IQ.

The etiological factors for anaemia vary geographically. Nutritionally related iron deficiency is the main cause of anaemia throughout the world'. Besides poor nutrition frequent child birth with close birth spacing, abortions, ,low educational status, late booking, poor socioeconomic status, parasitic infections and pica have been described as factors contributing to anaemia in pregnancy in various studies $^{2,12,13,14}$.

The management and control of anaemia in pregnancy can be enhanced by the availability of local prevalence statistics. This is the first study conducted in district Gujrat, aiming to determine the prevalence and various risk factors associated with maternal anaemia at the booking visit in Aziz Bhatti Shaheed teaching hospital. 
The findings could be useful for the health policy makers, clinicians and other health care providers towards reducing the frequency of anaemia and its related complications.

\section{MATERIALS AND METHODS}

This was a descriptive study carried out at Aziz Bhatti Shaheed (DHQ) teaching Hospital Gujrat. It is a 322 bedded hospital established in 1963 and declared as teaching hospital in 2008 after establishment of Nawaz Sharif Medical College. It is the main referral hospital of district Gujrat which has a total population of 2.4 million.

A total of 560 patients who attended the antenatal clinic for booking from $1^{\text {st }}$ Jan 2012 to July $31^{\text {st }} 2012$ were included in the study. Informed consent was obtained prior to commencement of interview. A detailed questionnaire was filled by the attending doctor during patient history taking. Gestational age was calculated from the date of last menstrual period and in patients who were unsure of dates symphysiofundal height or ultrasound scan was used for estimation of gestational age. Blood samples were taken for complete blood counts at the same visit. Patients with multiple pregnancies, those who were booked somewhere else and referred due to some complication or who refused investigation at first visit were excluded from the study.

Anaemia was labeled when haemoglobin was $<11 \mathrm{~g} / \mathrm{dl}$ and was further categorized as mild $(\mathrm{Hb}=9$ $10.9 \mathrm{~g} / \mathrm{dl})$, moderate $(\mathrm{Hb}=7-8.9 \mathrm{~g} / \mathrm{dl})$ and severe $(\mathrm{Hb}<7 \mathrm{~g} / \mathrm{dl})$ degree. Stool and urine examinations were done where indicated. Further investigations like haemoglobin electrophoresis, serum ferritin, serum iron and TIBC were done in few cases only due to nonaffordability of patients.

Statistical analysis was performed using the computer software Statistical Package for social Sciences (SPSS) for windows version 16. Statistical significance was set at p value $<0.05$.

\section{RESULTS}

Out of 987 pregnant women seen in outpatient department 560 women fulfilled the inclusion criteria. Among these 141 women were non-anaemic and 419 were anaemic giving a $74.8 \%$ prevalence of anaemia. The mean age of anaemic and non-anaemic women was 27.6yr and 25.6 year respectively. A total of 189(33.7\%) primi-gravidae and $371(66.2 \%)$ multigravidae were enrolled in the study. Anaemia was present in 131 primi-gravidae and 288 multi-gravidae giving a prevalence of $69.3 \%$ ) and $77.6 \%$ in primigravidae and multi-gravidae respectively $(p=0.032)$. (Table-I).

Table II shows that among the anaemic women prevalence of mild, moderate and severe anaemia was $69.9 \%, 26.7 \%$ and $3.3 \%$ respectively .Majority of primigravidae $(75 \%)$ had mild anaemia as compared to multigravidae (67.7\%),showing an increased severity of anaemia in multigravidae $(p=0.028)$ No case of severe anaemia was noted in primigravidae. The anaemia was more prevalent in those women who had birth interval $<$ yyear $(84.7 \%)$ or between 1 $<2$ years $(85.7 \%)$ compared to those who had birth interval of $2-<3$ years(68.8\%) or $>3$ years $(66.1 \%)$ showing an inverse relationship that was statistically significant $(P=.001)$ (Table-I).

A higher number 345(61.6\%) of women registered for antenatal care in $3^{\text {rd }}$ trimester compared to $72(12.8 \%)$ in $1^{\text {st }}$ and $143(25.5 \%)$ in $2^{\text {nd }}$ trimester .Prevalence of anaemia was44 (61.1\%), 101 (70.6\%) and 274 $(79.4 \%)$ in those who were booked in $1^{\text {st }}, 2^{\text {nd }}$ and $3^{\text {rd }}$ trimesters, reflecting an increased prevalence with late booking $(p=0.002)$. (Table-I)

Regarding education status out of 560 women 305 (54.46\%) had no formal education, 187 (33.4\%) and $68(12.40 \%)$, were educated up to primary and secondary school and higher secondary school. The 
anaemia was higher among those who were uneducated $240(78.6 \%)$ or educated up to primary 135 (72.2\%).The difference was statistically significant $(p=0.033)$ (Table-l).

The factors studied other than these sociodemographic factors were dietary habits regarding frequency of intake of chicken/ meat, pica and history of blood loss (menorrhagia, haemorrhoid, antepartum haemorrhage and postpartum haemorrhage).(table-III) overall 309(55.2\%) women took meat $\geq 2$ times per week. The anaemia was more prevalent in those who took chicken/meat $<2$ times per week $201(80 \%)$ ) than those who took it $\geq 2$ times per week $218(70.6 \%)) .(p=0.01)$. There was history of pica intake in $128(22.8 \%)$ women, $108(19.2 \%)$

\begin{tabular}{|c|c|c|c|c|}
\hline Characteristics & Non-anaemic & Anaemic & Total & P-value \\
\hline \multicolumn{5}{|l|}{ Parity } \\
\hline Primigravidae & $58(30.6 \%)$ & $131(69.3 \%)$ & $189(100 \%)$ & \multirow{3}{*}{0.032} \\
\hline Multigravidae & $83(22.4 \%)$ & $288(77.6 \%)$ & $371(100 \%)$ & \\
\hline Total & $141(25.2 \%)$ & $419(74.8 \%)$ & $560(100 \%)$ & \\
\hline \multicolumn{5}{|c|}{ Gestational age at booking } \\
\hline $1^{\text {st }}$ trimester & $28(38.9 \%)$ & $44(61.1 \%)$ & $72(100 \%)$ & \multirow{4}{*}{0.002} \\
\hline $2^{\text {nd }}$ trimester & $42(29.45 \%)$ & $101(70.6 \%)$ & $143(100 \%)$ & \\
\hline $3^{\text {rd }}$ trimester & $71(20.6 \%)$ & $274(79.4 \%)$ & $345(100 \%)$ & \\
\hline Total & $141(25.2 \%)$ & $419(74.8 \%)$ & $560(100 \%)$ & \\
\hline \multicolumn{5}{|l|}{ Birth interval } \\
\hline$<1 \mathrm{yr}$ & $9(15.3 \%)$ & $50(84.7 \%)$ & $59(100 \%)$ & \multirow{5}{*}{0.001} \\
\hline $1-<2 y r$ & $21(14.3 \%)$ & $126(85.7 \%)$ & $147(100 \%)$ & \\
\hline $2-<3 y r$ & $34(31.2 \%)$ & $75(68.8 \%)$ & $109(100 \%)$ & \\
\hline$\geq 3 \mathrm{yr}$ & $19(33.9 \%)$ & $37(66.1 \%)$ & $56(100 \%)$ & \\
\hline Total & $83(22.4 \%)$ & $288(77.6 \%)$ & $371(100 \%)$ & \\
\hline \multicolumn{5}{|l|}{ Education } \\
\hline No formal education & $65(21.3 \%)$ & $240(78.6 \%)$ & $305(100 \%)$ & \multirow{4}{*}{0.033} \\
\hline Primary & $52(27.8 \%)$ & $135(72.2 \%)$ & $187(100 \%)$ & \\
\hline $\begin{array}{l}\text { Secondary and } \\
\text { High secondary } \\
\text { school }\end{array}$ & $24(35.3 \%)$ & $44(64.7 \%)$ & $68(100 \%)$ & \\
\hline Total & $141(25.2 \%)$ & $419(74.8 \%)$ & $560(100 \%)$ & \\
\hline
\end{tabular}

Table-I. Prevalence of anaemia in pregnancy by maternal characteristics 
anaemic and $20(3.6 \%)$ non-anaemic $(p=0.005)$. (table-III). History of blood loss was present in 66(11.7\%) women, 53(9.5\%) were anaemic and $13(2.3 \%)$ were non-anaemic, but the difference was not statistically significant $(p=0.275)$.

\section{DISCUSSION}

The high prevalence of anaemia (74.8\%) revealed in this study is pin indication that anaemia during pregnancy is a major health problem in district Gujrat. Baig-Ansari N and Rohra DK have also shown a high prevalence $(91 \%)$ ) of anaemia in their studies at Hyderabad, Karachi and Nawab Shah ${ }^{12,15}$. In contrast study of Ayub $\mathrm{R}$ at shifa International Hospital Islamabad has shown that $42.5 \%$ pregnant women were anaemic ${ }^{16}$. The difference may be because that study was conducted in capital city of Pakistan where the level of awareness and education of antenatal clinic attendees varies. A similar high rate of $76.5 \%$ of anaemia was found in a study by Idowu OA in Nigeria at booking visit ${ }^{17}$.

Anaemia in majority $(70 \%)$ of our women was mild while only $3.3 \%$ ) had severe anaemia.WHO also reports an expected range of $1-5 \%$ of severe anaemia $^{18}$. Study of Baig-Ansari has also shown that

\begin{tabular}{|l|c|c|c|c|c|}
\hline \multicolumn{1}{|c|}{ Gravida } & Mild & Moderate & Severe & Total & P-value \\
\hline Primigravidae & $98(75 \%)$ & $33(25 \%)$ & - & $131(100 \%)$ & \multirow{2}{*}{0.028} \\
\cline { 1 - 5 } Multigravidae & $195(67.7 \%)$ & $79(27.4 \%)$ & $14(4.8 \%)$ & $288(100 \%)$ & \\
\cline { 1 - 5 } Total & $293(69.9 \%)$ & $112(26.7 \%)$ & $14(3.3 \%)$ & $419(100 \%)$ & \\
\hline
\end{tabular}

\begin{tabular}{|c|c|c|c|c|}
\hline Risk factor & Non-anaemic & Anaemic & Total & P-value \\
\hline \multicolumn{5}{|c|}{ Intake meat or chicken } \\
\hline$\geq 2$ Times / Wk & $91(29.4 \%)$ & 218 (70.6\%) & $309(100 \%)$ & \multirow{3}{*}{0.01} \\
\hline$<2$ Times / Wk & $50(19.9 \%)$ & 201 (80.1\%) & $251(100 \%)$ & \\
\hline Total & $141(25.2 \%)$ & 419 (74.8\%) & $560(100 \%)$ & \\
\hline \multicolumn{5}{|l|}{ Pica } \\
\hline Yes & $20(15.6 \%)$ & $108(84.4 \%)$ & $128(100 \%)$ & \multirow{3}{*}{0.005} \\
\hline No & $121(28 \%)$ & $311(72 \%)$ & $432(100 \%)$ & \\
\hline Total & $141(25.2 \%)$ & 419 (74.8\%) & $560(100 \%)$ & \\
\hline \multicolumn{5}{|c|}{ History of blood loss } \\
\hline Yes & $13(19.7 \%)$ & $53(80.3 \%)$ & $66(100 \%)$ & \multirow{3}{*}{0.275} \\
\hline No & $128(26 \%)$ & $366(64 \%)$ & $494(100 \%)$ & \\
\hline Total & $141(25.2 \%)$ & 419 (74.8\%) & $560(100 \%)$ & \\
\hline
\end{tabular}


$75 \%$ women had mild anaemia but incidence of severe anaemia in her study was only $0.7 \%{ }^{12}$. Nwizu EN had also noted no case of severe anaemia in Kano, Northern Nigeria ${ }^{14}$.

Anaemia was more prevalent among multigravidae as compared to primigravidae. In another study anaemia frequency was highest in those with four or more live births $^{2}$. More cases of moderate to severe anaemia were observed in multigravidae than in primigravidae concurrent to findings of Uche-Nwachi EO at Trinidad and Tobago ${ }^{19}$. Adequate birth spacing was also lacking in our women .Frequency of anaemic patients decreased from $84.7 \%$ to $66.1 \%$ with increasing birth interval from $<1$ year to $\geq 3$ years in our study.GN Okuwu has also shown that pregnant women with birth interval of <1year and 1-1.5years has significantly lower mean Haemoglobin while parity did not effect prevalence of anaemia in his study. Prior births may deplete maternal iron stores due to increased nutritional requirement of pregnancy and puerperal blood loss. The short interval between pregnancies delays the mother's recovery from the effects of previous pregnancies thus increasing the risk of maternal depletion syndrome. Since the foetal requirements are met first the mother is left with further depleted iron stores and anaemia develops. It has been shown that exhausted maternal stores at the end of one pregnancy takes about 2 years to be replenished .Breast feeding further depletes the iron stores.

There was a trend of late booking among pregnant women. Total $61.6 \%$ were booked in 3rd trimester out of which $79.4 \%$ were anaemic. Late booking is recognized as a risk factor for anaemia in other studies as well ${ }^{14,19}$. Late booking places the women and health care providers in a difficult situation due to limited time for optimum correction of any observed anaemia. The government and health care providers should use effective media to improve awareness of community about importance of early booking in pregnancy.
Only $45.6 \%$ of our pregnant women had any formal education and only $12.1 \%$ of them were educated above primary level. The anaemia prevalence of pregnant women decreased from $78.6 \%$ to $64.7 \%$ with increasing education level from no formal education to Matric and above. The finding is consistent with those of GN okuwu's study which showed a high prevalence of anaemia among the less educated women (no formal education and educated upto primary) $(p<0.0136)^{20}$.The reason may be that educated women have better understanding of importance of balanced diet .hygiene and sanitation and thus have reduced risk of infections. They have more awareness of importance of birth spacing and the methods used for that.

The most common cause of anaemia in pregnancy is iron deficiency. Iron in the meat is in heme form, and is highly bioavailable so inadequate iron intake especially reduced assess to heme iron can contribute to anaemia. Our study has shown a significant relationship of reduced frequency of intake of meat /chicken with increased risk of anaemia. Similarly a large survey in Vietnam had shown that meat consumption less than 3 times per week in women of reproductive age was associated with high prevalence of anaemia ${ }^{21}$. Abbassi RM found nutritional deficiency in $76.4 \%$ of anaemic gravidas ${ }^{13}$. Baig-Ansari $\mathrm{N}$ had also shown significant relationship of reduced frequency of meat intake and low mean haemoglobin concentration in pregnancy ${ }^{12}$.

Pica, the craving and purposive consumption of substances that the consumer does not define as food, is a widespread phenomenon that has been documented in nearly all cultures. In our study $22.8 \%$ women gave history of pica(soil eating, raw rice, peanut shells),out of which 19.2\%) were anaemic .showing a strong relationship of anaemia with pica intake .In a study of Young SL pica was seen in $41.6 \%$ of patients and had a strong association with low mean haemoglobin concentration and iron deficiency 
anaemia ${ }^{22}$.

We were unable to investigate other causes of anaemia like worm infestation and beta thalassemia in all anaemic cases due to non-compliance and nonaffordability of majority of our patients. The incidence of bete thalassemia minor is around $5 \%$ in Pakistan and its carriers present with mild anaemia .Further studies are required for these factors.

\section{CONCLUSIONS}

Anaemia is a major health problem in pregnant women .High parity, lack of birth spacing, late booking, lack of education, low protein intake and unhealthy eating habits are all contributing factors. Health education will lead to increased awareness and utilization of antenatal care and family planning services. Women should be educated about importance of early booking, use of iron pills during pregnancy and healthy eating habits through mass media and health workers to improve the current situation. Husbands are very powerful in decision making process in our culture so they need to be educated on the importance of providing permission, support and actual involvement in maternal health care including antenatal care and family planning.

\section{Copyright@ 25 Apr, 2013.}

\section{REFERENCES}

1. DeBenoist B, McLean E, Egli I, Cogswell M: Worldwide prevalence of anaemia 1993-2005: WHO global database on anaemia. Geneva: WHO; 2008.

2. Karaoglu L, Pehlivan E, Egri M, Deprem C, Gunes G, Gene MF etal. The prevalence of nutritional anaemia in pregnancy in an east Anatolian province. Turkey. BMC Public Health 2010; 10:329.

3. Kalaivani K. Prevalence and consequences of anaemia in pregnancy. Indian J Med Res 2009 Nov; 130(5):627-33.

4. $\quad$ Okeke $\mathrm{PL}$ ). Anaemia in pregnancy-is it a persisting public health problem in Porto Novo-Cape verde? Research Journal of Medical Sciences 2011; vol 5 (4):p193-99.

5. Sharma JB. Nutritional anaemia during pregnancy in non-industrialized countries. In: Progress in obstetrics and gynaecology 15: John Studd(ed) Churchill livingstone2003; 103-20.

6. Elhassan EM,I Abbaker A0, Haggaz AD, Abubaker MS, Adam I. Anaemia and low birth weight in Madani Hospital Sudan. BMC Research Notes 2010;28:187.

7. Haggaz AD, Radi EA, Adam I; Anaemia and low birth weight in Western Sudan. Trans R Soc Trop Med Hyg 2010; 104: 234-36.

8. Kidaento $\mathrm{HL}$, Mogren I, Lindmark G, Mussawe S ,Nystrom L. Risk for preterm delivery and low birth weight are independently increased by severity of maternal anaemia. S Afr Med J 2009; 99(2):98-102.

9. Ali AA, Adam I. Anaemia and still birth in Kassala Hospital, Eastern Sudan. J Trop Pediator 2011; 57(1): 62-4.

10. Ali AA, Rayis DA, Abdullah TM, Elbashir Ml, Adam I: Severe anaemia is associated with a high risk for preeclampsia and poor perinatal outcomes in Kassala Hospital, Eastern Sudan. BMC Research Notes 2011; 4: 311. ( ttp:// www, biomedcentral.com/1756-0500/ $4 / 311)$.

11. Bakhtiar UJ, Khan Y, Nasar R. Relationship between maternal haemoglobin and perinatal outcome. Rawal Medical Journal 2007; 32(2); 102-4.

12. Baig-Ansari N, Badruddin SH, Karmaliani R, Harris H, Jehan I, Pasha 0 et al. Anaemia prevalence and risk factors in pregnant women in an urban area of Pakistan. Food and Nutrition Bulletin. 2008; 29(2): 132-9.

13. Abbassi RM, Ansari S, Devrajani BR, Abbasi S. The prevalence and risk factors of anaemia in pregnant women. Medical Channel July-Sep 2009; vol 15(3): 70-3.

14. Nwizu EN, lliyasu Z, Ibrahim SA, Galadanci HS. Sociodemographic and maternal factors in anaemia in pregnancy at booking in Kano, northern Nigeria. African Journal of Reproductive Health Dec 2011; 15(4):33-41. 
15. Rohra Dk, Solangi NA, Memon Z, Khan NH, Azam SI, Anuja KL. Haemoglobin status of pregnant women visiting tertiary care hospitals of Pakistan. Pak J MedRes. 2008; vol 47(2):33-6.

16. Ayub R, Tariq N, Adil MM, lqbal M, Jaferry T, Rais SR. Low haemoglobin levels, its determinants and associated features among pregnant women in Islamabad and surrounding region. J Pak Med Assoc 2009 Feb; vol 59(2):p86-9.

17. Idowu OA, Mafiana CF, Sotiloye D. Anaemia in pregnancy: A survey of pregnant women in Abeokuta, Nigeria. Afr Health Sci. 2005 Dec; 5(4):295-99.

18. WHO. Prevention and management of severe anaemia in pregnancy: report of technical working group Geneva. WHO 1993(WHO/FHF/MSM/93-5).

19. Uche-Nwachi E0, Odekunle A, Jacinto S, Burnett M,
Clapperton M, David Y etal. Anaemia in pregnancy: Associations with parity, abortions and child spacing in primary health care clinic attendees in Trinidad and Tobago. African Health Sciences Mar 2010; Vol 10(1):66-70.

20. Okwu GN, Ukoha Al. Studies on the pre-disposing factors of iron deficiency anaemia among pregnant women in a Nigerian community. Pakistan Journal of nutrition 2008; 7(1): 151-56.

21. Nguyen PH, Nguyen KG, Le Mai B, Nguyen TV, Ha KH, Bern $C$ etal. Risk factors for anaemia in Vietnam. Southeast Asian J Trop Med Public Health 2006; 37:1213-23.

22. Young SL, Khalfan SS, Faraq TH, Kavle JA, Ali SM, Hajji $\mathrm{H}$ etal. Association of pica with anaemia and gastrointestinal distress among pregnant women in Zanzibar, Tanzania. Am J Trop Med Hyg.2010 July; 83(1):144-51.
AUTHOR(S):

1. DR. SHABANA KALSOOM

Senior Registrar Obst \& Gynae

Nawaz Sharif Medical College Gujrat

2. DR. SHAHIDA HUSSAIN TARAR

Assistant Professor Obst. \& Gynae Nawaz Sharif Medical College Gujrat

3. DR. TAHMINA NAZ

Senior Registrar Obst \& Gynae

Nawaz Sharif Medical College Gujrat
Correspondence Address:

Dr. Shabana Kalsoom

H.No. C-674 Lane No.16, Lalarukh

Wah Cantt

shabanakalsoom@hotmail.com

\section{PREVIOUS RELATED STUDIES}

ljaz ul Haque Taseer, Sohail Safdar, Ahsanullah Mir Bahar, Zara Awan. ANEMIA IN PREGNANCY; RELATED RISK FACTORS IN UNDER DEVELOPEDAREA(Original) Prof Med Jour 18(1) 1-4 Jan, Feb, Mar 2011. 